\title{
Nebivolol: impact on cardiac and endothelial function and clinical utility
}

This article was published in the following Dove Press journal:

Vascular Health and Risk Management

12 March 2012

Number of times this article has been viewed

\author{
Jorge Eduardo Toblli' \\ Federico DiGennaro' \\ Jorge Fernando Giani² \\ Fernando Pablo Dominici ${ }^{2}$ \\ 'Hospital Aleman, ${ }^{2}$ Instituto de \\ Química y Fisicoquímica Biológicas \\ (IQUIFIB), Facultad de Farmacia y \\ Bioquímica, Facultad de Medicina, \\ Universidad de Buenos Aires, \\ Buenos Aires, Argentina
}

Correspondence: Jorge E Toblli Laboratory of Experimental Medicine, Hospital Alemán, School of Medicine, University of Buenos Aires, Av Pueyrredon 1640 (II I8) Buenos Aires, Argentina Tel +54 II 4827 7000, ext 2276 Email jorgetoblli@fibertel.com.ar

\begin{abstract}
Endothelial dysfunction is a systemic pathological state of the endothelium characterized by a reduction in the bioavailability of vasodilators, essentially nitric oxide, leading to impaired endothelium-dependent vasodilation, as well as disarrangement in vascular wall metabolism and function. One of the key factors in endothelial dysfunction is overproduction of reactive oxygen species which participate in the development of hypertension, atherosclerosis, diabetes, cardiac hypertrophy, heart failure, ischemia-reperfusion injury, and stroke. Because impaired endothelial activity is believed to have a major causal role in the pathophysiology of vascular disease, hypertension, and heart failure, therapeutic agents which modify this condition are of clinical interest. Nebivolol is a third-generation $\beta$-blocker with high selectivity for $\beta 1$-adrenergic receptors and causes vasodilation by interaction with the endothelial L-arginine/ nitric oxide pathway. This dual mechanism of action underscores several hemodynamic qualities of nebivolol, which include reductions in heart rate and blood pressure and improvements in systolic and diastolic function. Although nebivolol reduces blood pressure to a degree similar to that of conventional $\beta$-blockers and other types of antihypertensive drugs, it may have advantages in populations with difficult-to-treat hypertension, such as patients with heart failure along with other comorbidities, like diabetes and obesity, and elderly patients in whom nitric oxide-mediated endothelial dysfunction may be more pronounced. Furthermore, recent data indicate that nebivolol appears to be a cost-effective treatment for elderly patients with heart failure compared with standard care. Thus, nebivolol is an effective and well tolerated agent with benefits above those of traditional $\beta$-blockers due to its influence on nitric oxide release, which give it singular hemodynamic effects, cardioprotective activity, and a good tolerability profile. This paper reviews the pharmacology structure and properties of nebivolol, focusing on endothelial dysfunction, clinical utility, comparative efficacy, side effects, and quality of life in general with respect to the other antihypertensive agents.
\end{abstract}

Keywords: beta-blockers, nebivolol, oxidative stress, endothelial function, cardiovascular protection, nitric oxide

\section{Endothelial dysfunction and cardiovascular risk}

The endothelium regulates vascular homeostasis by elaborating a number of paracrine factors responsible for maintaining normal vascular tone, and blood fluidity, and limiting vascular inflammation and smooth muscle cell proliferation. ${ }^{1,2}$ Unquestionably, nitric oxide is considered to be a key contributor to vascular health in many ways, including inhibition of platelet aggregation, monocyte adhesion to endothelial cells, and abnormal smooth muscle cell proliferation. ${ }^{3,4}$

Nitric oxide is generated from L-arginine by the action of endothelial nitric oxide synthase in the presence of cofactors, such as tetrahydrobiopterin. Once nitric oxide 
is produced, it diffuses to vascular smooth muscle cells and activates guanylate cyclase, which leads to cGMP-mediated vasodilatation (Figure 1). ${ }^{5,6}$ Additionally, nitric oxide is involved in several protective functions of the endothelium by limiting vascular inflammation, vascular smooth muscle proliferation, platelet aggregation, and production of tissue factors. $^{6,7}$ Therefore, modifications of normal endothelial physiology result in endothelial dysfunction, which is characterized by a decrease in the bioavailability of vasodilators, especially nitric oxide. In agreement with this concept, endothelial dysfunction is currently recognized as a risk factor for atherosclerosis, representing an integrated index of both the overall cardiovascular risk factor burden and the sum of all vasculoprotective factors in an individual. ${ }^{7,8}$

The activation of $\beta$-adrenoreceptors on the endothelium stimulates nitric oxide synthesis by endothelial nitric oxide synthase. Interestingly, it has been demonstrated that overexpression of endothelial nitric oxide synthase could paradoxically be maladaptive by leading to oxidative stress through synthesis of the superoxide anion. ${ }^{9}$

It is worth mentioning that permanent $\beta$-adrenoreceptor activation could exacerbate endothelial nitric oxide synthase activity and expression although, in turn, it causes endothelial nitric oxide synthase uncoupling that would change into a source of superoxide anion generation. At the same time, there is convincing evidence suggesting that reduced nitric oxide bioavailability following sympathetic hyperactivity and/or increased plasma catecholamine levels is the major contributor to endothelial dysfunction (Figure 2). Production of superoxide anions by uncoupled endothelial nitric oxide synthase and inflammatory mediator synthesis induced by chronic $\beta$-adrenergic activation seem to play an essential role in the endothelial dysfunction induced by sympathetic overflow. Consequently, both mechanisms may be therapeutic targets in cardiovascular disease associated with endothelial dysfunction and sympathetic hyperactivity. ${ }^{10,11}$

\section{Pharmacology of nebivolol}

Beta-blockers are among the most widely used drugs for prevention and treatment of cardiovascular disease. ${ }^{12-15}$ They comprise a varied group of antihypertensive medications, including drugs that block the action of epinephrine and norepinephrine on both $\beta_{1}$-adrenergic and $\beta_{2}$-adrenergic receptors, and are thus considered to be nonselective (eg, propranolol, which was the first $\beta$-blocker introduced into clinical practice). Although it is effective in the treatment of hypertension, propranolol has major side effects associated mainly with its capability of blocking $\beta_{2}$-adrenergic receptors, particularly at the respiratory level and also due to its ability to cross the blood-brain barrier. ${ }^{16,17}$ This has led to the development and introduction of second-generation drugs with selective effects on $\beta_{1}$-cardiac receptors and no effects on vasodilation, eg, atenolol and metoprolol. ${ }^{18-21}$ In general, traditional $\beta$-blockers have a

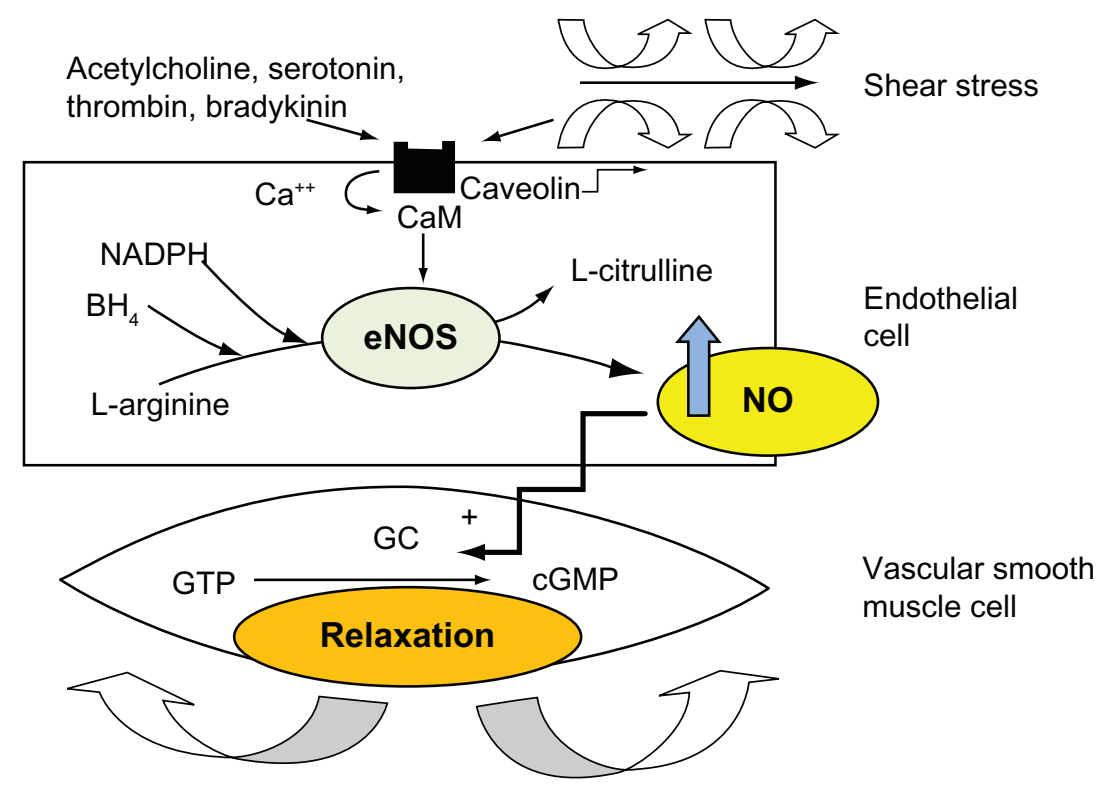

Figure I Synthesis of nitric oxide by endothelial cells. Nitric oxide is produced by the action of endothelial nitric oxide synthase on L-arginine. Several cofactors, including tetrahydrobiopterin $\left(\mathrm{BH}_{4}\right)$ and nicotinamide adenine dinucleotide phosphate, are required to generate this reaction. Endothelial nitric oxide synthase is activated as a consequence of the dislodgement of the inhibitor caveolin from calmodulin in response to vasodilator agonists or shear stress. Nitric oxide diffuses to vascular smooth muscle and produces relaxation through activation of guanylate cyclase, thus augmenting intracellular cyclic guanosine monophosphate.

Abbreviations: eNOS, endothelial nitric oxide synthase; NO, nitric oxide; NADPH, reduced nicotinamide adenine dinucleotide phosphate; CaM, calmodulin; GTP, guanosine 5'-triphosphate; GC, guanylate cyclase; cGMP, cyclic guanosine monophosphate. 
A
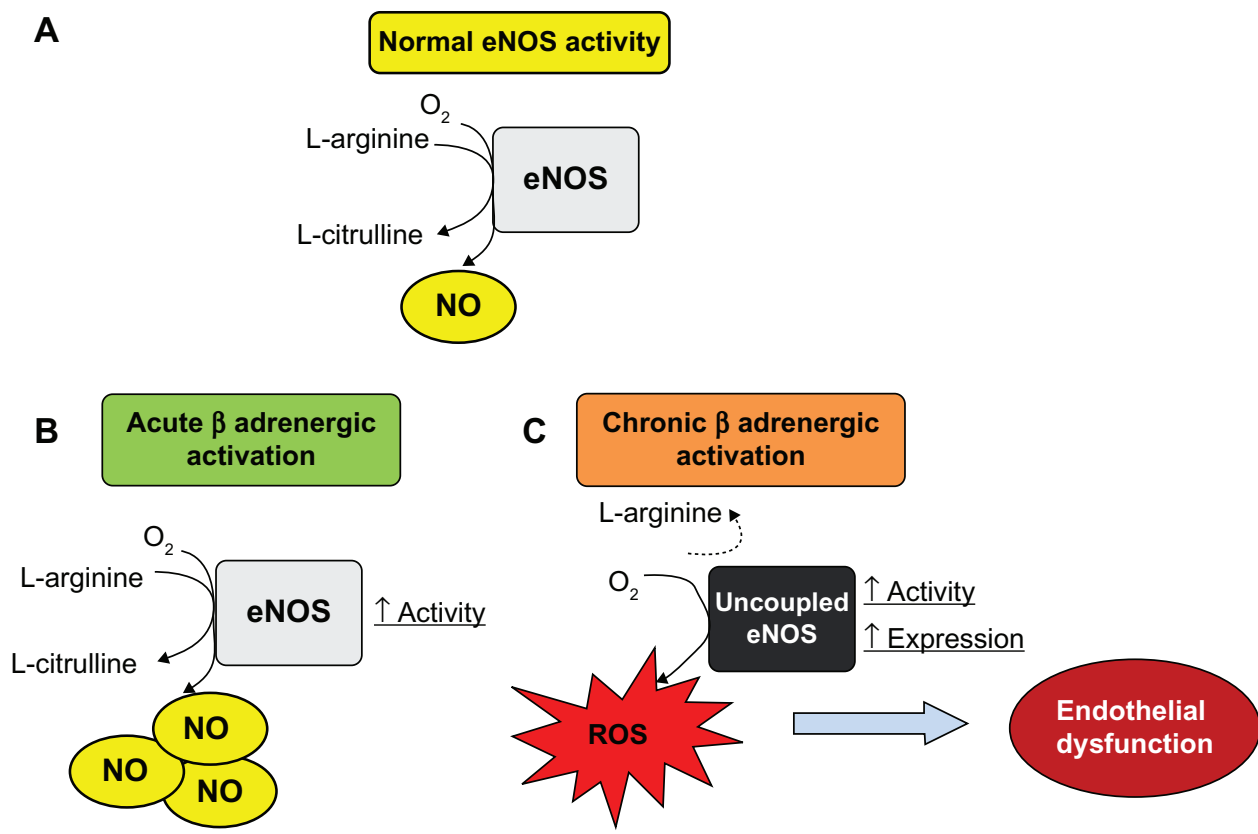

Figure 2 Effect of acute and chronic $\beta$-adrenergic activation on endothelial nitric oxide synthase activity, expression, and uncoupling. (A) In normal conditions, basal endothelial nitric oxide synthase activity oxidizes L-arginine, generating L-citrulline and nitric oxide at physiological rates which contributes to maintenance of vascular tone in healthy vessels. (B) Acute $\beta$-adrenergic activation caused by $\beta$-adrenoceptor agonists stimulates endothelial nitric oxide synthase activity and could increase release of endothelial nitric oxide. (C) Permanently high catecholamine levels could lead to overactivation of $\beta$-adrenoceptors, increasing activity and protein expression of endothelial nitric oxide synthase. Nevertheless, this condition may lead to uncoupling of endothelial nitric oxide synthase, which produces superoxide anions and peroxynitrite (reactive oxygen species). Abbreviations: eNOS, endothelial nitric oxide synthase; NO, nitric oxide; ROS, reactive oxygen species.

poorer clinical impact compared with other classes of drugs. Notably, they have a low impact on quality of life, and a negative effect on carbohydrate and lipid metabolism. The blockade of $\beta_{1}$-adrenergic receptors can induce dyslipidemia because these receptors participate in the mechanism of lipolysis in adipocytes. Thus, pharmacological research on this type of drug has continued, seeking a $\beta$-blocker with the additional characteristic of inducing peripheral vasodilation. This line of investigation has led to the development of third-generation $\beta$-blockers that differ in the mechanisms by which they exert vasodilation.

The most studied and used third-generation $\beta$-blocker with vasodilating effects is carvedilol. Although it is useful in the treatment of heart failure, carvedilol antagonizes $\alpha_{1}$-adrenergic receptors but has a combined antagonistic effect on both $\beta_{1}$ - and $\beta_{2}$-receptors. ${ }^{22,23}$ Blockade of $\beta_{2}$-receptors generates side effects such as fatigue and dizziness, thus limiting its use. Therefore, the pharmacologic, mechanistic, and hemodynamic differences between conventional nonvasodilating $\beta$-blockers and vasodilating $\beta$-blockers have important implications, particularly in the treatment of complicated hypertension, such as that associated with diabetes or the cardiometabolic syndrome. The effects of these agents on endothelial dysfunction may be the main contributing factor in these differences.
Nebivolol is the third-generation $\beta$-blocker with the greatest selectivity for cardiac $\beta_{1}$-adrenergic receptors and the highest $\beta_{1}-/ \beta_{2}$-selectivity compared with other $\beta$-blockers assessed ex vivo, and because it has no effect on $\alpha$-receptors, it is devoid of intrinsic sympathomimetic activity. ${ }^{24,25}$ Given its characteristics, nebivolol reduces blood pressure and peripheral vascular resistance and does not depress, but rather tends to maintain or improve, left ventricular function in healthy subjects and in patients with hypertension by increasing cardiac output and stroke volume, reducing systemic vascular resistance, and improving diastolic function. ${ }^{26-31}$

Nebivolol also possesses endothelium-dependent arterial and venous vasodilator properties that are largely attributed to stimulation of nitric oxide production..$^{31}$ Importantly, participation of $\alpha$-adrenergic receptors in these effects has been ruled out, while showing that the mechanism of action of nebivolol proceeded through a different mechanism of action from that of carvedilol. ${ }^{32,33}$ The first demonstration of this effect was in isolated canine coronary arteries, showing that vasodilation mediated by nebivolol is endotheliumdependent and abrogated by a nitric oxide inhibitor. ${ }^{31}$ Later, various studies corroborated the importance of nitric oxide in the vasodilatory action of nebivolol in humans. The venous dilation induced by nebivolol was prevented by inhibitors 
of nitric oxide synthase. ${ }^{32}$ Similar results were found for the arterial circulation. ${ }^{33-35}$ Treatment with nebivolol was shown to be linked to increased activity of the endothelial isoform of endothelial nitric oxide synthase, suggesting participation of this enzyme in the vasodilating effects of this drug. ${ }^{36}$ These effects were confirmed by the observation that nitric oxide production in vascular tissues increases after stimulation with nebivolol. ${ }^{37,38}$ Importantly, this pharmacological aspect of nebivolol does not depend on activation of $\beta 1$ receptors and is not shared by other drugs of the same class. The ability of nebivolol to enhance or restore nitric oxide-mediated vasodilation in hypertensive patients has important therapeutic implications in view of the well established protective role of nitric oxide against cardiovascular risk factors, and particularly the development of atherosclerosis..$^{39,40}$

Nebivolol also stimulates nitric oxide production in the heart. ${ }^{41}$ The effects of nebivolol on cardiac production of nitric oxide does not depend on inhibition of $\beta_{1}$-adrenergic receptors because cardiac nitric oxide is not induced by other drugs of the same functional class. Nebivolol cannot evoke nitric oxide production in the heart in the presence of a $\beta_{3}$-adrenergic receptor antagonist. Its actions on cardiac tissue are mediated via stimulation of $\beta_{3}$-adrenenergic receptors to release nitric oxide and promote neoangiogenesis. ${ }^{41}$ Thus, the $\beta_{3}$-adrenergic receptor has emerged as a potential target for the treatment of heart disease. ${ }^{42,43}$ The cardioprotective effects of nebivolol may prove particularly beneficial for the treatment of ischemic and heart failure diseases via preservation of coronary reserve. ${ }^{44}$ Indeed, recent studies have demonstrated that nebivolol as well as two other specific $\beta_{3}$-adrenegic agonists protect against myocardial ischemiareperfusion injury via rapid activation of endothelial and neuronal nitric oxide synthase and increased nitric oxide bioavailability. ${ }^{45}$

Nebivolol is a racemic mixture containing equal amounts of two isomers, ie, d-nebivolol and 1-nebivolol (Figure 3). Animal and human pharmacological experiments have demonstrated that the antihypertensive and hemodynamic action of the racemic mixture is superior to that of the isomers alone. ${ }^{46-49}$ The $\beta_{1}$-blocking effects of nebivolol reside in the $\mathrm{d}$-isomer, while the inhibition of exerciseinduced tachycardia is evident with the racemic mixture. ${ }^{49}$ The nitric oxide-releasing effect of nebivolol is mainly due to its 1-enantiomer. ${ }^{46,47}$ The racemate and its enantiomers possess remarkable antioxidant activity that contributes to its effect on metabolism of cellular nitric oxide. ${ }^{48}$ Nebivolol also scavenges reactive oxygen species in a receptorindependent manner by direct interaction with free radicals. Nebivolol has been shown to reduce the concentration of superoxide anion in endothelial cells. ${ }^{50}$ This effect has also been detected in experimental animal models ${ }^{51-53}$ and in patients. ${ }^{54,55}$ By scavenging reactive oxygen species, nebivolol not only reduces oxidant stress but also augments nitric oxide bioavailability. The attenuation of oxidative stress attained with the administration of nebivolol is also associated with a reduction in peroxynitrites. ${ }^{53,54}$ Nebivolol has also been shown to inhibit $\mathrm{NAD}(\mathrm{P}) \mathrm{H}$ oxidase activity in various models of hypertension, including angiotensin II-treated rats, spontaneously hypertensive rats, and transgenic rats overexpressing renin. ${ }^{52-54}$ This is another mechanism by

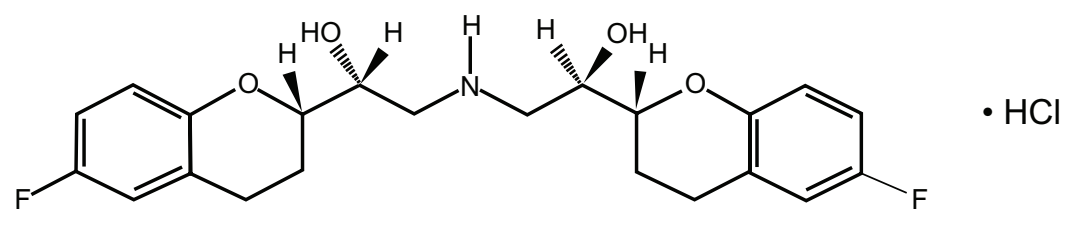

$S, R, R, R$ - or d-nebivolol hydrochloride

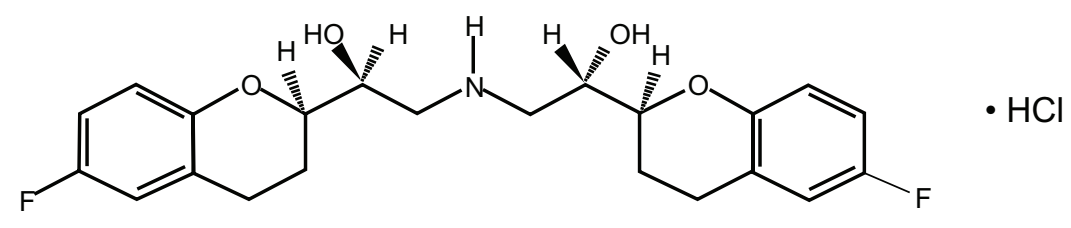

R,S,S,S - or I-nebivolol hydrochloride

MW: $441.90 \mathrm{~g} / \mathrm{mol}$

Figure 3 Chemical structure of the two isomers of nebivolol as a hydrochloride salt. Nebivolol has four asymmetric centers; the $d$-isomer refers to (S,R,R,R)-nebivolol and the l-isomer to (R,S,S,S)-nebivolol. The enantiomers have unequal potency with regard to $\beta$-receptor blocking activity and nitric oxide-mediated vasodilation. Abbreviation: MW, molecular weight. 
which the drug may reduce excessive $\mathrm{O}_{2}^{-}$production and the oxidative stress milieu that typifies hypertension. Therefore, the endothelial nitric oxide synthase-stimulating and reactive oxygen species-scavenging effects of nebivolol act synergistically to provide cardiovascular protection in addition to its $\beta_{1}$-antagonistic action (Figure 4).

Nebivolol causes downregulation of a number of genes involved in the inflammatory process, oxidative stress, and smooth muscle cell proliferation. ${ }^{55-57}$ Such antiproliferative effects have clear implications in the modulation of vascular structure, including cavernous tissue,${ }^{58}$ with obvious inference in erectile dysfunction linked to cardiovascular disease.

It has been documented that $\beta$-adrenergic antagonists can influence platelet aggregation by a mechanism independent of their ability to antagonize beta-adrenoceptors. ${ }^{59-62} \mathrm{~A}$ recent study in Zucker diabetic fatty fa/fa rats indicate that platelet aggregation was significantly reduced by treatment with nebivolol in comparison with atenolol. ${ }^{63}$ In agreement with this experimental finding, a study in human platelets showed that although nebivolol, propranolol, and carvedilol all had an inhibitory effect on both ADP-induced and collagen-induced platelet aggregation, nebivolol exhibited the greatest inhibition effect on platelet aggregation. The mechanism responsible for the inhibitory effect of nebivolol appears to involve a nitric oxide-dependent pathway because L-arginine augments the inhibitory effects of nebivolol on platelet aggregation. Furthermore, the inhibitory effect of nebivolol on platelet aggregation is reduced in the presence of the nitric oxide synthase inhibitor, N (G)-monomethyl-Larginine. Thus, the mechanism by which nebivolol inhibits platelet aggregation differs from that of other $\beta$-adrenergic antagonists by being partially dependent on nitric oxide production. ${ }^{62}$ The beneficial effects of nebivolol on platelet activation are more potent than those of other $\beta$-blockers, such as metoprolol. ${ }^{64}$ Therefore, decreased platelet activation with nebivolol might play a role in reducing thrombotic risk in hypertensive patients.

\section{Clinical efficacy and tolerability}

Nebivolol has been developed and studied for three basic indications, ie, heart failure, arterial hypertension, and coronary artery disease. Regarding heart failure, convincing information indicates that $\beta$-blocker therapy diminishes 5 -year mortality and morbidity by approximately one third in heart failure patients, by causing a reduction in adrenergic drive, modulation of sympathovagal balance and rate variability, and improvement of cardiac performance. However, $\beta$-blocker therapy has important side effects

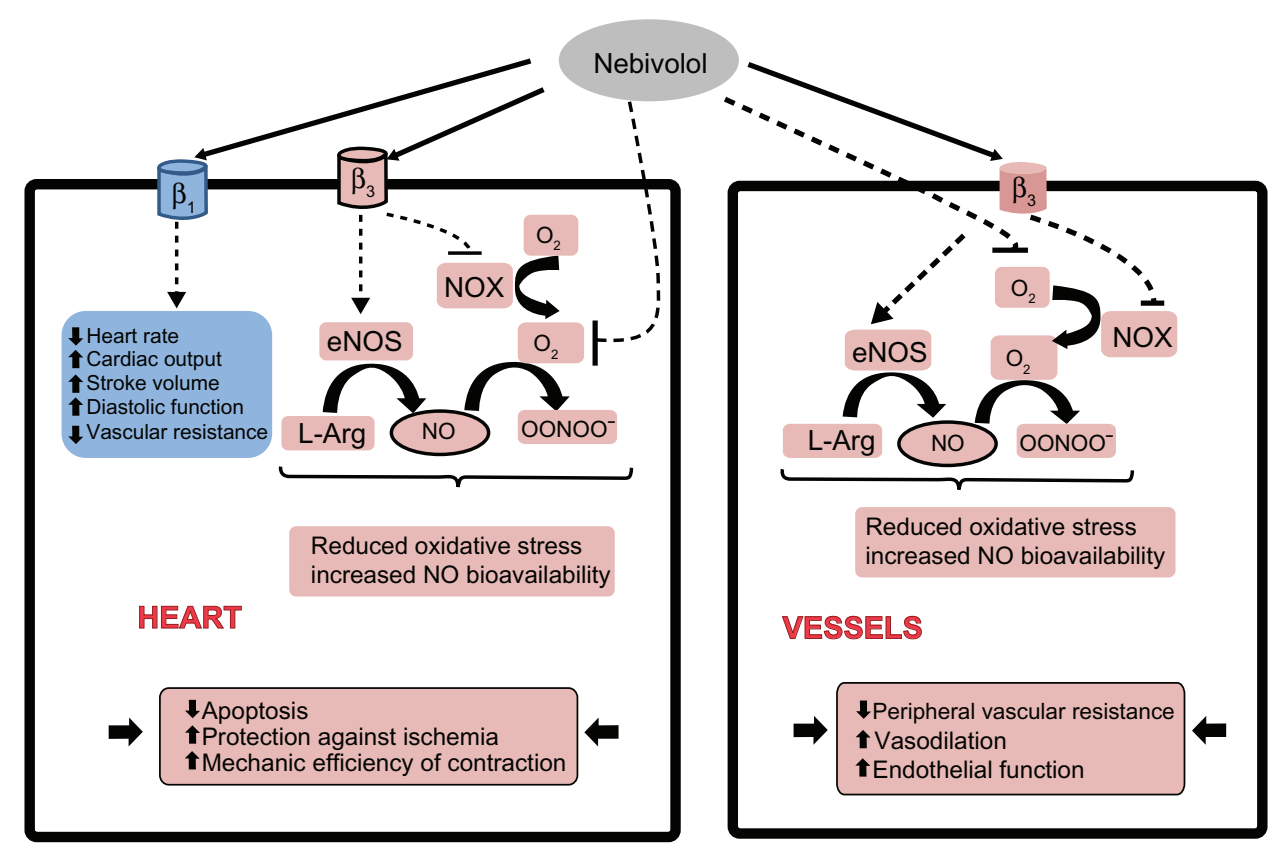

Figure 4 Mechanisms of action of nebivolol in the cardiovascular system. Antagonism of cardiac $\beta_{1}$-adrenergic receptors by nebivolol maintains or improves left ventricular function in healthy subjects and in patients with hypertension by decreasing heart rate, increasing cardiac output, and stroke volume. In addition, nebivolol protects health by reducing oxidative stress and increasing nitric oxide bioavailability through nonreceptor dependent scavenging of $\mathrm{O}_{2}^{-}$and $\beta_{3}$-adrenergic receptor-dependent inhibition of NADPH oxidase and endothelial nitric oxide synthase uncoupling. In the vasculature, nebivolol acts through $\beta_{3}$-adrenergic receptors to augment nitric oxide bioavailability and exerts a direct scavenging effect, leading to vasodilation and an improvement of endothelial function.

Notes: $" \cdot \cdots \cdot \rightarrow$ stimulation, " $" \cdot \cdots \cdot$ inhibition.

Abbreviations: NADPH, reduced nicotinamide adenine dinucleotide phosphate; NOX, NADPH oxidase; eNOS, endothelial nitric oxide synthase; NO, nitric oxide. 
in these patients. ${ }^{65}$. The major inconvenience is due to the negative inotropic and chronotropic effects of these compounds. Notably, while other $\beta$-blockers mostly act by reducing stroke volume, nebivolol and carvedilol preserve left ventricular function, maintain stroke volume and cardiac output, produce peripheral vasodilation, and maintain cardiac chronotropism during exertion. ${ }^{66-69}$ Additionally, unlike classical $\beta$-blockers, some reports indicate that nebivolol has a neutral or beneficial effect on hemodynamic parameters, such as mean pulmonary artery pressure and pulmonary wedge pressure. ${ }^{70,71}$ The benefits of nebivolol for heart failure treatment have been evaluated in SENIORS (Study of Effects of Nebivolol Intervention on Outcomes and Rehospitalization in Seniors With Heart Failure), where more than 2000 patients aged $\geq 70$ years with a history of heart failure (hospital admission for heart failure within the previous year or known ejection fraction $\leq 35 \%$ ) were randomized to nebivolol $(\mathrm{n}=1067)$ titrated from $1.25 \mathrm{mg}$ to $10 \mathrm{mg}$ once daily or placebo $(\mathrm{n}=1061)$. The primary outcome was a composite of all-cause mortality or cardiovascular hospital admission (time to first event), and mean duration of follow-up was 21 months. Nebivolol was effective and well tolerated in elderly patients with heart failure. ${ }^{72}$

With respect to the antihypertensive effect of nebivolol, various randomized, double-blind, placebo-controlled trials have evaluated its efficacy and tolerability. Nebivolol was evaluated in a large open-label, 6-week follow-up study of 6356 patients with mild-to-moderate essential hypertension or isolated systolic hypertension, recruited from 2700 facilities. In this cohort of patients, the efficacy of nebivolol was very similar not only as monotherapy, but also as addon therapy. Furthermore, 5-10 mg of nebivolol therapy showed a mild impact on diastolic blood pressure. ${ }^{73}$ Consequently, this valuable modulation of diastolic blood pressure underscores that nebivolol is highly effective, especially in patients with isolated systolic hypertension, and has a good safety profile.

Interestingly, a multicenter, double-blind, randomized, parallel-group, placebo-controlled, dose-ranging study ( $5 \mathrm{mg}, 10 \mathrm{mg}, 20 \mathrm{mg}$ once daily for 12 weeks) investigated the antihypertensive efficacy and safety of nebivolol monotherapy in patients with stage I through stage II hypertension. ${ }^{74}$ Although the outcomes indicated that nebivolol was more effective than placebo at such doses, analysis of the response rates revealed that once-daily nebivolol $5 \mathrm{mg}, 10 \mathrm{mg}$, and $20 \mathrm{mg}$ showed mild differences between them $(66.0 \%, 66.8 \%$, and $68.9 \%$, respectively). This finding suggests that higher doses of $5 \mathrm{mg}$ do not provide substantially better results. Moreover, while the $5 \mathrm{mg}$ and $10 \mathrm{mg}$ doses were well tolerated, with an overall adverse event incidence comparable with that of placebo, the $20 \mathrm{mg}$ dose was associated with an increase in adverse events in comparison with placebo. In contrast with this observation, a recent study in self-identified Hispanic patients with stage I-II hypertension who were randomized to receive a double-blind treatment (placebo or nebivolol 5-40 mg/day) showed comparable adverse effects in both groups. ${ }^{75}$

When compared with other antihypertensive drugs, such as calcium antagonists or other $\beta$-blockers, nebivolol achieved similar control in blood pressure with fewer side effects, especially in elderly subjects. A meta-analysis of 12 randomized controlled studies showed that nebivolol $5 \mathrm{mg}$ achieved similar or better rates of treatment response and blood pressure normalization than other drug classes and other antihypertensive drugs combined, with tolerability similar to that of placebo and significantly better tolerability than losartan, calcium antagonists, other $\beta$-blockers, and all antihypertensive drugs combined. ${ }^{76}$ The onset of the maximal antihypertensive effect of nebivolol takes places after 2-8 weeks of therapy, which is intermediate between amlodipine (faster) and angiotensin-converting enzyme inhibitors (slower).

Unfortunately, large studies in isolated systolic hypertension are currently not available. This topic is of paramount importance given that recent information suggests neutral or comparatively worse effects of $\beta$-blockers on mortality and morbidity in patients with arterial hypertension. ${ }^{77}$ Consequently, at present, due to the lack of sufficient data to support utilization of $\beta$-blockers as first-line antihypertensive drugs, use of this class of agents remains controversial.

Concerning the therapeutic properties for coronary artery disease, nebivolol, as a third-generation $\beta$-blocker, has a vasodilating capacity and improves hyperemic coronary blood flow. This occurs as a result of a decline in minimal resistance, which can be assigned to $\alpha$-adrenergic blockade and/or to a nitric oxide-mediated effect. Hence, this therapeutic action clearly has a positive effect in patients with coronary artery disease. Interestingly, in animal models of experimental ischemia and reperfusion injury, nebivolol has been shown to have protective effects. ${ }^{78}$ Moreover, in humans, it has been demonstrated that treatment with nebivolol is more effective in improving exercise tolerance and time to onset of angina during exercise testing when compared with atenolol. ${ }^{79}$ In agreement with this, because nebivolol improves coronary microvascular function, a secondary 
benefit of improvement in left ventricular function could be expected in those patients with angina pectoris or silent ischemia. However, unfortunately, information regarding the impact of nebivolol on mortality and morbidity in coronary artery disease is not available at present.

\section{Comparative impact on cardiovascular risk}

Experimental data in animals with metabolic syndrome indicate that nebivolol has an actual protective role, not only in cardiovascular structures but also in renal tissue, in comparison with atenolol. ${ }^{58,63,80}$ Evaluation of immunoexpression of plasminogen activator inhibitor-1 and cell adhesion molecules, such as VCAM-1 and PECAM-1, in the vascular wall of diabetic rats which received nebivolol for 6 months showed favorable modification of these prothrombotic and vascular inflammatory markers when compared with atenolol. ${ }^{63}$ Because nitric oxide regulates the expression of cell adhesion molecules, and increased levels of nitric oxide are associated with decreased expression of adhesion molecules, it would be understandable that treatment with nebivolol causes an actual profit on vascular structures in a hyperlipidemic and hyperglycemic environment.

In clinical studies, it has been reported that whereas atenolol considerably increased cholesterol and triglyceride levels, nebivolol decreased serum triglycerides, with a favorable effect on the cholesterol profile. ${ }^{81}$ Persistent hypertriglyceridemia has a deleterious effect on the $\beta$-cell in the pancreas (lipotoxicity), and this, together with the metabolic environment of diabetes, may contribute to accelerating the negative effect on islet function. Therefore, a favorable modification in the lipid status by nebivolol may preserve the pancreatic $\beta$-cell metabolism in this scenario. In addition, because insulin resistance is commonly associated with endothelial dysfunction and exposure of vascular endothelium to high circulating levels of lipids and glucose is accompanied by reduced nitric oxide availability, the most likely mechanism for the differences between nebivolol and atenolol with respect to metabolic profile would be the ability of nebivolol to increase nitric oxide bioavailability, as demonstrated in animals and hypertensive patients. ${ }^{82}$

Recently, the antihypertensive efficacy and effects of nebivolol alone and in association with hydrochlorothiazide on glucose and lipid metabolism in hypertensive patients were assessed. An improvement in glucose metabolism was noted with nebivolol alone, ie, a significant reduction in homeostasis model assessment-insulin resistance, and adjunctive use of hydrochlorothiazide blunted this reduction.
No significant changes in the lipid profile were noted with nebivolol, either alone or in combination therapy. ${ }^{83}$ This information is particularly relevant to the management of patients resistant to monotherapy in order to optimize blood pressure control without a negative impact on glucose and lipid profiles.

The effects of nebivolol and influence of diabetes mellitus and hyperglycemia on the prognosis in elder patents ( $\geq 70$ years) with heart failure was recently reported in a subanalysis of SENIORS. ${ }^{84}$ The conclusion was that elder patients with heart failure and diabetes mellitus had a worse prognosis. Nebivolol was less effective in patients with diabetes and heart failure than in those with heart failure but without diabetes.

\section{Patient-focused perspectives}

Quality of life is an increasingly important tool in assessing treatment effects and allocating resources to where they are most effective. Given that the benefits of antihypertensive treatment and therapy for heart failure are long-term and any discomfort of having to take daily medication is immediate, a therapeutic agent with positive overall effects on quality of life should have as little negative influence on patients' everyday lives as possible. The greatest impact on quality of life was reported for cardiovascular drugs with side effects, such as reduced exercise capacity, emotional distress, alterations in sexual function, insomnia, tiredness, and depression.

A trial investigating three $\beta$-blockers showed that bisoprolol, but not nebivolol or carvedilol, decreased nocturnal release of melatonin, a phenomenon that may cause sleep disturbances. ${ }^{85}$ This study also showed that carvedilol slightly decreased quality of life, whereas nebivolol and bisoprolol had no influence, suggesting that different $\beta$-blockers exert different clinically relevant effects. In agreement with this, data from a prospective, randomized, open-label study on the impact of $\beta$-blockers on sleep in patients with mild hypertension indicate significant differences between nebivolol versus metoprolol. ${ }^{86}$ Eligible patients were administered the Pittsburgh Sleep Quality Index questionnaire by a blinded interviewer and were randomized to receive metoprolol or nebivolol. Interestingly, the patients treated with nebivolol showed improved sleep parameters whereas those treated with metoprolol showed detrimental effects. Considering that sleep is an important component of quality of life, it should be carefully taken into account during any therapeutic intervention.

It is widely accepted that administration of traditional $\beta$-blockers is one of the leading causes of drug-related 
erectile dysfunction. However, recent data indicate that patients treated with nebivolol obtained higher scores in every parameter of the International Index of Erectile Dysfunction questionnaire. Furthermore, treatment with nebivolol was associated with a lower prevalence of erectile dysfunction in this study. ${ }^{87}$ In another double-blind, randomized, parallelgroup study in more than 300 patients with hypertension, when nebivolol was compared with losartan, the effect on sexual function did not differ between these two treatments after 6 weeks of monotherapy. ${ }^{88}$

Concerning physical activity, when evaluated in the long term, nebivolol has been demonstrated to improve exercise capacity, especially in patients with hypertension and heart failure, at a similar level to carvedilol. ${ }^{89}$ However, in a recent randomized, placebo-controlled trial, exercise performance, evaluated by cardiopulmonary exercise, was better preserved with nebivolol than with carvedilol under acute exposure to high altitude (4559 m) hypoxia in healthy subjects. ${ }^{90}$

\section{Conclusion}

Although nebivolol reduces blood pressure to a degree similar to that of conventional $\beta$-blockers and other types of antihypertensive drugs, it may have advantages in populations with difficult-to-treat hypertension, such as diabetics, obese patients, and the elderly, in whom nitric oxide-mediated endothelial dysfunction may be more pronounced. Consequently, with the aim to achieve the best "tailor made" treatment for a patient with hypertension and heart failure together with other comorbidities, selection of the most suitable $\beta$-blocker is of paramount importance.

\section{Acknowledgment}

The authors thank Jaquelina Mastantuono for reviewing the style of this manuscript.

\section{Disclosure}

JET and FPD are researchers at the National Research Council of Argentina. JFG is a postdoctoral research fellow at the National Research Council of Argentina. No conflicts of interest, financial or otherwise, are declared by the authors.

\section{References}

1. Deanfield JE, Halcox JP, Rabelink TJ. Endothelial function and dysfunction: testing and clinical relevance. Circulation. 2007;115: $1285-1295$.

2. Bonetti PO, Lerman LO, Lerman A. Endothelial dysfunction: a marker of atherosclerotic risk. Arterioscler Thromb Vasc Biol. 2003;23:168-175.

3. Furchgott RF, Zawadzki JV. The obligatory role of endothelial cells in the relaxation of arterial smooth muscle by acetylcholine. Nature. 1980;288:373-376.
4. Yanagisawa M, Kurihara H, Kimura S, et al. A novel potent vasoconstrictor peptide produced by vascular endothelial cells. Nature. 1988;332:411-415.

5. Cooke JP, Tsao PS. Is NO an endogenous antiatherogenic molecule? Arterioscler Thromb. 1994;14:653-655.

6. Forstermann U, Munzel T. Endothelial nitric oxide synthase in vascular disease: from marvel to menace. Circulation. 2006;113: 1708-1714.

7. Ganz P, Vita JA. Testing endothelial vasomotor function: nitric oxide, a multipotent molecule. Circulation. 2003;108:2049-2053.

8. Anderson TJ. Assessment and treatment of endothelial dysfunction in humans. J Am Coll Cardiol. 1999;34:631-638.

9. Davel AP, Kawamoto EM, Scavone C, et al. Changes in vascular reactivity following administration of isoproterenol for 1 week: a role for endothelial modulation. Br J Pharmacol. 2006;148629-639.

10. Fukuda LE, Davel AP, Verissimo-Filho S, et al. Fenofibrate and pioglitazone do not ameliorate the altered vascular reactivity in aorta of isoproterenol-treated rats. J Cardiovasc Pharmacol. 2008;52: 413-421.

11. Ferro A, Queen LR, Priest RM, et al. Activation of nitric oxide synthase by beta 2 -adrenoceptors in human umbilical vein endothelium in vitro. Br J Pharmacol. 1999;126:1872-1880.

12. Law MR, Morris JK, Wald NJ. Use of blood pressure lowering drugs in the prevention of cardiovascular disease: meta-analysis of 147 randomised trials in the context of expectations from prospective epidemiological studies. Br Med J. 2009;338:b1665.

13. Kotseva K, Wood D, De Backer G, et al. EUROASPIRE III. Management of cardiovascular risk factors in asymptomatic high-risk patients in general practice: cross-sectional survey in 12 European countries. Eur J Cardiovasc Prev Rehabil. 2010;17:530-540.

14. Basile JN. One size does not fit all: the role of vasodilating beta-blockers in controlling hypertension as a means of reducing cardiovascular and stroke risk. Am J Med. 2010;123:S9-S15.

15. De Caterina AR, Leone AM. The role of beta-blockers as first-line therapy in hypertension. Curr Atheroscler Rep. 2011;13:147-153.

16. Olesen J, Hougård K, Hertz M. Isoproterenol and propranolol: ability to cross the blood-brain barrier and effects on cerebral circulation in man. Stroke. 1978;9:344-349.

17. Cruickshank JM, Neil-Dwyer G, Cameron MM, etal. Beta-adrenoreceptorblocking agents and the blood-brain barrier. Clin Sci. 1980;59 Suppl 6: $453 \mathrm{~s}-455 \mathrm{~s}$.

18. Hansson L, Aberg H, Karlberg BE, et al. Controlled study of atenolol in treatment of hypertension. Br Med J. 1975;5967:367-370.

19. Regårdh CG, Borg KO, Johansson R, et al. Pharmacokinetic studies on the selective betal-receptor antagonist metoprolol in man. J Pharmacokinet Biopharm. 1974;4:347-364.

20. Bengtsson C. The effect of metoprolol - a new selective adrenergic beta1-receptor blocking agent - in mild hypertension. Acta Med Scand. 1976;199:65-70.

21. Sharma V, Dhillon P, Wambolt R, et al. Metoprolol improves cardiac function and modulates cardiac metabolism in the streptozotocin-diabetic rat. Am J Physiol Heart Circ Physiol. 2008;294: H1609-H1620.

22. Fu GS, Huang H, Chen F, et al. Carvedilol ameliorates endothelial dysfunction in streptozotocin-induced diabetic rats. Eur J Pharmacol. 2007;567:223-230.

23. Eggertsen R, Sivertsson R, Andrén L, et al. Haemodynamic effects of carvedilol, a new beta-adrenoceptor blocker and precapillary vasodilator in essential hypertension. J Hypertens. 1984;2:529-534.

24. Van de Water A, Janssens W, Van Neuten J, et al. Pharmacological and hemodynamic profile of nebivolol, a chemically novel, potent, and selective beta 1-adrenergic antagonist. $J$ Cardiovasc Pharmacol. 1988;11:552-563.

25. Janssens WJ, Van de Water A, Xhonneux R, et al. Nebivolol is devoid of intrinsic sympathomimetic activity. Eur $J$ Pharmacol. 1989;159:89-95. 
26. Sorrentino SA, Doerries C, Manes C, et al. Nebivolol exerts beneficial effects on endothelial function, early endothelial progenitor cells, myocardial neovascularization, and left ventricular dysfunction early after myocardial infarction beyond conventional $\beta 1$-blockade. $J \mathrm{Am}$ Coll Cardiol. 2011;57:601-611.

27. McEniery CM, Schmitt M, Qasem A, et al. Nebivolol increases arterial distensibility in vivo. Hypertension. 2004;44:305-310.

28. Edes I, Gasior Z, Wita K. Effects of nebivolol on left ventricular function in elderly patients with chronic heart failure: results of the ENECA study. Eur J Heart Fail. 2005;4:631-639.

29. Fountoulaki K, Dimopoulos V, Giannakoulis J, et al. Left ventricular mass and mechanics in mild-to-moderate hypertension: effect of nebivolol versus telmisartan. Am J Hypertens. 2005;18:171-177.

30. Ignarro LJ, Byrns RE, Trinh K, et al. Nebivolol: a selective beta(1)adrenergic receptor antagonist that relaxes vascular smooth muscle by nitric oxide- and cyclic GMP-dependent mechanisms. Nitric Oxide. 2002;7:75-82.

31. Gao YS, Nagao T, Bond RA. Nebivolol induces endothelium-dependent relaxations of canine coronary arteries. J Cardiovasc Pharmacol. 1991;17:964-969.

32. Bowman AJ, Chen CP, Ford GA. Nitric oxide mediated venodilator effects of nebivolol. Br J Clin Pharmacol. 1994;38:199-204.

33. Cockcroft JR, Chowienczyk PJ, Brett SE, et al. Nebivolol vasodilates human forearm vasculature: evidence for an L-arginine/NO-dependent mechanism. J Pharmacol Exp Ther. 1995;274:1067-1071.

34. de Groot AA, Mathy MJ, van Zwieten PA, et al. Involvement of the beta3 adrenoceptor in nebivolol-induced vasorelaxation in the rat aorta. Cardiovasc Pharmacol. 2003;42:232-236.

35. Tzemos N, Lim PO, MacDonald TM. Nebivolol reverses endothelial dysfunction in essential hypertension: a randomized, double-blind, crossover study. Circulation. 2001;104:511-514.

36. Parenti A, Filippi S, Amerini S, et al. Inositol phosphate metabolism and nitric-oxide synthase activity in endothelial cells are involved in the vasorelaxant activity of nebivolol. J Pharmacol Exp Ther. 2000;292:698-703.

37. Maffei A, Vecchione C, Aretini A, et al. Characterization of nitric oxide release by nebivolol and its metabolites. Am J Hypertens. 2006;19:579-586.

38. Broeders MA, Doevendans PA, Bekkers BC, et al. Nebivolol: a third-generation beta-blocker that augments vascular nitric oxide release: endothelial beta(2)-adrenergic receptor-mediated nitric oxide production. Circulation. 2000;102:677-684.

39. Dubois-Randé JL, Zelinsky R, Roudot F, et al. Effects of infusion of L-arginine into the left anterior descending coronary artery on acetylcholine-induced vasoconstriction of human atheromatous coronary arteries. Am J Cardiol. 1992;70:1269-1275.

40. Dawes M, Brett SE, Chowienczyk PJ, et al. The vasodilator action of nebivolol in forearm vasculature of subjects with essential hypertension. Br J Clin Pharmacol. 1999;48:460-463.

41. Maffei A, Di Pardo A, Carangi R, et al. Nebivolol induces nitric oxide release in the heart through inducible nitric oxide synthase activation. Hypertension. 2007;50:652-656.

42. Gauthier C, Tavernier G, Charpentier F, et al. Functional beta3adrenoceptor in the human heart. J Clin Invest. 1996;98:556-562.

43. Rozec B, Gauthier C. Beta3-adrenoceptors in the cardiovascular system: putative roles in human pathologies. Pharmacol Ther. 2006;111: 652-673.

44. Erdogan D, Gullu H, Caliskan M, et al. Nebivolol improves coronary flow reserve in patients with idiopathic dilated cardiomyopathy. Heart. 2007;93:319-324.

45. Aragón JP, Condit ME, Bhushan S, et al. Beta(3)-adrenoreceptor stimulation ameliorates myocardial ischemia-reperfusion injury via endothelial nitric oxide synthase and neuronal nitric oxide synthase activation. J Am Coll Cardiol. 2011;58:2683-2691.

46. Sacco G, Evangelista S, Criscuoli M, et al. Involvement of nitric oxide in both central and peripheral haemodynamic effect of D/L-nebivolol and its enantiomers in rats. Eur J Pharmacol. 2005;511:167-174.
47. Evangelista S, Garbin U, Pasini AF, et al. Effect of DL-nebivolol, its enantiomers and metabolites on the intracellular production of superoxide and nitric oxide in human endothelial cells. Pharmacol Res. 2007;55:303-309.

48. Ignarro LJ. Different pharmacological properties of two enantiomers in a unique beta-blocker, nebivolol. Cardiovasc Ther. 2008;26:115-134.

49. Van Nueten L, De Crée J. Nebivolol: comparison of the effects of dl-nebivolol, d-nebivolol, 1-nebivolol, atenolol, and placebo on exerciseinduced increases in heart rate and systolic blood pressure. Cardiovasc Drugs Ther. 1998;4:339-344.

50. Cominacini L, Fratta Pasini A, Garbin U, et al. Nebivolol and its 4-keto derivative increase nitric oxide in endothelial cells by reducing its oxidative inactivation. J Am Coll Cardiol. 2003;42:1838-1844.

51. Mollnau H, Schulz E, Daiber A, et al. Nebivolol prevents vascular NOS III uncoupling in experimental hyperlipidemia and inhibits NADPH oxidase activity in inflammatory cells. Arterioscler Thromb Vasc Biol. 2003;23:615-621.

52. Oelze M, Daiber A, Brandes RP, et al. Nebivolol inhibits superoxide formation by NADPH oxidase and endothelial dysfunction in angiotensin II-treated rats. Hypertension. 2006;48:677-684.

53. Mason RP, Kubant R, Jacob RF, et al. Effect of nebivolol on endothelial nitric oxide and peroxynitrite release in hypertensive animals: role of antioxidant activity. $J$ Cardiovasc Pharmacol. 2006;48:862-869.

54. Whaley-Connell A, Habibi J, Johnson M, et al. Nebivolol reduces proteinuria and renal NADPH oxidase-generated reactive oxygen species in the transgenic Ren2 rat. Am J Nephrol. 2009;30:354-360.

55. Brehm BR, Bertsch D, von Fallois J, Wolf SC. Beta-blockers of the third generation inhibit endothelin-1 liberation, mRNA production and proliferation of human coronary smooth muscle and endothelial cells. J Cardiovasc Pharmacol. 2000;36:S401-S403.

56. Brehm BR, Wolf SC, Bertsch D, et al. Effects of nebivolol on proliferation and apoptosis of human coronary artery smooth muscle and endothelial cells. Cardiovasc Res. 2001;49:430-439.

57. Wolf SC, Sauter G, Jobst J, et al. Major differences in gene expression in human coronary smooth muscle cells after nebivolol or metoprolol treatment. Int J Cardiol. 2008;125:4-10.

58. Toblli JE, Cao G, Casas G, et al. In vivo and in vitro effects of nebivolol on penile structures in hypertensive rats. Am J Hypertens. 2006;19: 1226-1232.

59. Srivastava KC. Influence of some beta blockers (pindolol, atenolol, timolol and metoprolol) on aggregation and arachidonic acid metabolism in human platelets. Prostaglandins Leukot Med. 1987;29:79-84.

60. Gasser JA, Betterridge DJ. Comparison of the effects of carvedilol, propranolol, and verapamil on in vitro platelet function in healthy volunteers. J Cardiovasc Pharmacol. 1991;18 Suppl 4:S29-S34.

61. Ignjatovic VS, Petrovic N, Miloradovic V, et al. The influence of bisoprolol dose on ADP-induced platelet aggregability in patients on dual antiplatelet therapy. Coron Artery Dis. 2010;21:472-476.

62. Falciani M, Rinaldi B, D'Agostino B, et al. Effects of nebivolol on human platelet aggregation. J Cardiovasc Pharmacol. 2001;38:922-929.

63. Toblli JE, Cao G, Rivas C, et al. Cardiovascular protective effects of nebivolol in Zucker diabetic fatty rats. J Hypertens. 2010;28: 1007-1019.

64. Celik T, Yuksel UC, Iyisoy A, et al. Effects of nebivolol on platelet activation in hypertensive patients: a comparative study with metoprolol. Int J Cardiol. 2007;116:206-211.

65. Shibata MC, Flather MD, Wang D. Systematic review of the impact of beta blockers on mortality and hospital admissions in heart failure. Eur J Heart Fail. 2001;3:351-357.

66. Kamp O, Sieswerda GT, Visser CA. Comparison of effects on systolicand diastolic left ventricular function of nebivolol versus atenolol in patients with uncomplicated essential hypertension. Am J Cardiol. 2003;92:344-348.

67. Wisenbaugh T, Katz I, Davis J, et al. Long-term (3-month) effects of a new beta-blocker (nebivolol) on cardiac performance in dilated cardiomyopathy. J Am Coll Cardiol. 1993;21:1094-1100. 
68. Uhlir O, Dvorak I, Gregor P, et al. Nebivolol in the treatment of cardiac failure: a double-blind controlled clinical trial. J Card Fail. 1997;3:271-276.

69. Zanchetti A. Clinical pharmacodynamics of nebivolol: new evidence of nitric oxide-mediated vasodilating activity and peculiar haemodynamic properties in hypertensive patients. Blood Press. 2004;Suppl 1: 17-32.

70. Nodari S, Metra M, Dei Cas L. Beta-blocker treatment of patients with diastolic heart failure and arterial hypertension. A prospective, randomized, comparison of the long-term effects of atenolol vs nebivolol. Eur J Heart Fail. 2003;5:621-627.

71. Brune S, Schmidt T, Tebbe U, et al. Hemodynamic effects of nebivolol at rest and on exertion in patients with heart failure. Angiology. 1990;41:696-701.

72. Flather MD, Shibata MC, Coats AJ, et al. Randomized trial to determine the effect of nebivolol on mortality and cardiovascular hospital admission in elderly patients with heart failure (SENIORS). Eur Heart J. 2005;26:215-225.

73. Cleophas TJ, Agrawal R, Lichtenthal A, et al. Nationwide efficacysafety study of nebivolol in mildly hypertensive patients. Am J Ther. 2006;13:192-197.

74. Greathouse M. Nebivolol efficacy and safety in patients with stage I-II hypertension. Clin Cardiol. 2010;33:E20-E27.

75. Punzi H, Lewin A, Lukić T, et al. Efficacy and safety of nebivolol in Hispanics with stage I-II hypertension: a randomized placebocontrolled trial. Ther Adv Cardiovasc Dis. 2010;4:349-357.

76. Van Bortel LM, Fici F, Mascagni F. Efficacy and tolerability of nebivolol compared with other antihypertensive drugs: a meta-analysis. Am J Cardiovasc Drugs. 2008;8:35-44.

77. Bangalore S, Sawhney S, Messerli FH. Relation of beta-blocker induced heart rate lowering and cardioprotection in hypertension. J Am Coll Cardiol. 2008;52:1482-1489.

78. Vandeplassche G, Lu HR, Wouters L, et al. Normothermic ischemic cardiac arrest in the isolated working rabbit heart: effects of dl-nebivolol and atenolol. Basic Res Cardiol. 1991;86:21-31.

79. Van Bortel LM, van Baak MA. Exercise tolerance with nebivolol and atenolol. Cardiovasc Drugs Ther. 1992;6:239-247.

80. Toblli JE, Cao G, Giani JF, et al. Long-term treatment with nebivolol attenuates renal damage in Zucker diabetic fatty rats. J Hypertens. 2011;29:1613-1623.
81. Rizos E, Bairaktari E, Kostoula A, et al. The combination of nebivolol plus pravastatin is associated with a more beneficial metabolic profile compared with that of atenolol plus pravastatin in hypertensive patients with dyslipidemia: a pilot study. J Cardiovasc Pharmacol Ther. 2003;8: $127-134$

82. Agabiti Rosei E, Rizzoni D. Metabolic profile of nebivolol, a beta adrenoceptor antagonist with unique characteristics. Drugs. 2007;67:1097-1107.

83. Marazzi G, Volterrani M, Caminiti G, et al. Effectiveness of nebivolol and hydrochlorothiazide association on blood pressure, glucose, and lipid metabolism in hypertensive patients. Adv Ther. 2010;27:655-664.

84. de Boer RA, Doehner W, van der Horst IC, et al. SENIORS Investigators. Influence of diabetes mellitus and hyperglycemia on prognosis in patients $>$ or $=70$ years old with heart failure and effects of nebivolol (data from the Study of Effects of Nebivolol Intervention on Outcomes and Rehospitalization in Seniors with heart failure [SENIORS]). Am J Cardiol. 2010;106:78-86.

85. Stoschitzky K, Stoschitzky G, Brussee H, et al. Comparing betablocking effects of bisoprolol, carvedilol and nebivolol. Cardiology. 2006;106:199-206.

86. Yilmaz MB, Erdem A, Yalta K, et al. Impact of beta-blockers on sleep in patients with mild hypertension: a randomized trial between nebivolol and metoprolol. Adv Ther. 2008;25:871-883.

87. Cordero A, Bertomeu-Martínez V, Mazón P, et al. Erectile dysfunction in high-risk hypertensive patients treated with beta-blockade agents. Cardiovasc Ther. 2010;28:15-22.

88. Van Bortel LM, Bulpitt CJ, Fici F. Quality of life and antihypertensive effect with nebivolol and losartan. Am J Hypertens. 2005;18:1060-1066.

89. Marazzi G, Volterrani M, Caminiti G, et al. Comparative long term effects of nebivolol and carvedilol in hypertensive heart failure patients. J Card Fail. 2011;17:703-709.

90. Valentini M, Revera M, Bilo G, et al. Effects of beta-blockade on exercise performance at high altitude: a randomized, placebo-controlled trial comparing the efficacy of nebivolol versus carvedilol in healthy subjects. Cardiovasc Ther. 2011. Epub March 11.
Vascular Health and Risk Management

\section{Publish your work in this journal}

Vascular Health and Risk Management is an international, peerreviewed journal of therapeutics and risk management, focusing on concise rapid reporting of clinical studies on the processes involved in the maintenance of vascular health; the monitoring, prevention and treatment of vascular disease and its sequelae; and the involvement of

\section{Dovepress}

metabolic disorders, particularly diabetes. This journal is indexed on PubMed Central and MedLine. The manuscript management system is completely online and includes a very quick and fair peer-review system, which is all easy to use. Visit http://www.dovepress.com/ testimonials.php to read real quotes from published authors. 